\title{
Clinical Study of 100cases of Caesarean Section in Tairunnessa Memorial Medical College \& Hospital. Gazipur
}

\author{
Begum RA ${ }^{1}$, Sultana $N^{2}$, Sultana $N^{3}$, Begum A ${ }^{4}$, Hossain $\mathrm{ME}^{5}$, Begum $\mathrm{S}^{6}$
}

\section{Abstract}

To find out the common indications of caesarean section and complications of this operation, both for mother and baby. This observational study was carried out on 100 cases of caesarean sections, who were operated in the Department of Obstetrics \& Gynaecology, Tairunnessa Memorial Medical College \& Hospital. Previous caesarean section and oligohydroamnios with fetal distress contribute the major causes of caesarean section. Contribute the major causes of caesarean section. Common complications are UTI, wound infection. Indications of caesarean section should be properly identified to decrease the unnecessary operation, which ultimately decrease indication of previous caesarean section. Maintenance of proper asepsis would avoid the complications of this operation.

Key words: Caesarean section, Indication, Complication

1. Corresponding Author: Dr. Rowshan Ara Begum Assistant Professor, Department of Obs \& Gynae Tairunnessa Memorial Medical College \& Hospital. e-mail:Azadbhuiyan10@gmail.com

2. Dr. Naireen Sultana Associate Professor, Department of Obs \& Gynae Tairunnessa Memorial Medical College \& Hospital.

3. Dr. Nahid Sultana Professor\& Head, Department of Obs \& Gynae Tairunnessa Memorial Medical College \& Hospital

4. Dr. Amena Begum (Lt.Col.) Consultant Border Guard Hospital, Pilkhana.

5. Dr. Mohammad Emran Hossain Associate Professor and Head Department of Forensic Medicine \& Toxicology Tairunnessa Memorial Medical College \&Hospital.

6. Dr. Sudhira Begum Professor (CC) and Head, Department of Pharmacology Tairunnessa Memorial Medical College \& Hospital.

\section{Introduction}

Caesarean section is an operative procedure where a baby is delivered by giving incision on anterior abdominal wall and uterus after 28 weeks of pregnancy ${ }^{1}$. Caesarean section was introduced in clinical practice as a life saving procedure both for mother and baby. As other procedures of some complexity, its use follows the health care inequity pattern of the world: under in low income setting and adequate or even unnecessary use in middle and high income setting ${ }^{2-5}$. There are many reasons why a doctor might feel that patient needs to have caesarean section. Some caesarean section occur in critical situation\& some are elective. The first modern caesarean section was done by German gynecologist Ferdinand Adlof Keher $1881^{6}$. The name of the procedure is said to derive from a Roman legal code "Lex Caesaren" which allegedly contained a law prescribing that the baby be cut out of its mother's womb in the case that she dies before giving birth ${ }^{7}$. It is necessary to find out the common indications and complications of caesarean section, because it is associated with high maternal and neonatal risk. It is important to set up a regular protocol and profile for accurate indications for caesarean section which can reduce the unnecessary caesarean section.

\section{Materials and Methods}

This prospective study was carried out is the Department of Obs \& Gynae, Tairunnessa Memorial Medical College \& Hospital, during the period of November 2013 to April 2014 among 100 cases of caesarean sections. The aim of this study is to find out the indications of caesarean section\& complications of it. For which 100 cases were selected for the study. Cases were selected in predesigned proforma. Preterm pregnancies were excluded due to lack of NICU facility in this institution. Indications of caesarean sections were detected antenataly, intranataly and it was compared with the findings of operation. Operation findings were noted, any complication was also noted. Puerperal period up to the end of the day of discharge was observed. Patient came again for post natal check up after seven days. Any complications in this period were noted.

\section{Result}

A total of 100 cases were obtained in the department of Obs \& Gynae, Tairunnessa Memorial Medical College \& Hospital, during six months period (Nov 2013-April 2014). 
Majority of the patients were between 26-30 yrs (31\%). Most of them were multipara (49\%). Commonest cause of caesarean section in this study was oligohydroamnios (36\%) followed by history of previous caesarean section (27\%). Most of the babies were healthy (74\%). Maternal complication after caesarean section was mainly UTI (17\%), followed by wound infection $11 \%$.

Table-1 shows that caesarean section were done most commonly among patients of age group 26-30years, next was 20-25 years.

Table -I: Distribution of patients according to age $(n=100)$.

\begin{tabular}{cll}
\hline Age Group(years) & No. of pt & Percentage \\
\hline$<20$ & 12 & $12 \%$ \\
$20-25$ & 26 & $26 \%$ \\
$26-30$ & 31 & $31 \%$ \\
$31-35$ & 18 & $18 \%$ \\
$36-40$ & 13 & $13 \%$ \\
\hline
\end{tabular}

Table-II shows multi gravid were under went caesarean section commonly, probably due to previous caesarean section.

Table-II: Distribution of patients according to number of parity $(\mathrm{n}=100)$ :

\begin{tabular}{llc}
\hline Parity & No. of $\mathbf{p t}$ & Percentage \\
\hline Primi gravid & 43 & $43 \%$ \\
Multi gravid & 49 & $49 \%$ \\
Grand multi gravid & 8 & $8 \%$ \\
\hline
\end{tabular}

Table-III shows that previous caesarean section about 27\% $\&$ amount of amniotic fluid contribute major indications for caesarean section. Some patients underwent caesarean section due to their desire.

Table-III: Distribution of patients according to indication of caesarean section $(n=100)$

\begin{tabular}{llc}
\hline Indications & No. of pt & Percentage \\
\hline Oligohydroamnios & 36 & $36 \%$ \\
Previous caesarean section. & 27 & $27 \%$ \\
Fetal distress. & 23 & $23 \%$ \\
Mal presentation & 17 & $17 \%$ \\
Failed Progress of labour including failed & 16 & $16 \%$ \\
induction. & 15 & \\
Severe pre eclampsia & 11 & $15 \%$ \\
Obstructed labour & 9 & $11 \%$ \\
Elective caesarean section & 9 & $9 \%$ \\
Abruptio placenta & 7 & $9 \%$ \\
Placenta praevia & 6 & $7 \%$ \\
Eclampsia & & $6 \%$ \\
\hline
\end{tabular}

Table-IV shows that majority of the babies delivered by caesarean section are healthy, but the rate of still birth is $2 \%$.

Table- IV: Distribution of patients according to fetal outcome $(n=100)$

\begin{tabular}{lcc}
\hline Condition of the baby & No. of case & Percentage \\
\hline Healthy & 74 & $74 \%$ \\
Low birth weight & 13 & $13 \%$ \\
Birth asphyxia & 7 & $7 \%$ \\
Early neonatal death & 4 & $4 \%$ \\
Still Birth & 2 & $2 \%$ \\
\hline
\end{tabular}

Table-V shows UTI is a common post operative complication in caesarean section, 2 nd one is wound infection.

Table-V: Distribution of patients according maternal complication after caesarean section $(n=100)$

\begin{tabular}{llc}
\hline Complications & No. of pt & Percentage \\
\hline UTI & 17 & $17 \%$ \\
Wound Infection & 11 & $11 \%$ \\
P.P.H & 8 & $8 \%$ \\
Post partum Eclampsia & 4 & $4 \%$ \\
Wound Dehiscence & 1 & $1 \%$ \\
Maternal death & 1 & $1 \%$ \\
\hline
\end{tabular}

Table VI shows maximum patient leave hospital within normal time limit.

Table-VI: Distribution of patients according to hospital stay $(n=100)$

\begin{tabular}{lc}
\hline Hospital stay(Days) & Percentage \\
\hline$<5$ days & $86 \%$ \\
$5-10$ days & $12 \%$ \\
$>10$ days & $2 \%$ \\
\hline
\end{tabular}

\section{Discussion}

Caesarean section is the most common obstetrical operation, the rate of caesarean section is gradually increasing throughout the world due to modern fetal monitoring technique with the advent of modern anesthesia and antibiotics. Obstetricians, fear of litigation may have made the changing rate and indications for caesarean section seem more acceptable. But caesarean section result in a small overall increase in bad outcomes in low risk pregnancies ${ }^{8}$. Analysis of the age group of the patients showed that $82 \%$ are at the age group of maximum fertility and lowest $12 \%$ in late fertility group. Caesarean section occurring more in multipara, usually with the history of previous caesarean section \& lowest in grand multipara In this institution maximum indication of caesarean section is due to fetal distress with severe oligohydroamnios, of which maximum babies were 
meconium stained with birth asphyxia and the lowest indication was elective caesarean section, most of them under went caesarean section to avoid stress of vaginal delivery. This Fetal outcome of study was very good, only

$2 \%$ were still birth. Most of the patients leave hospital with healthy baby. The incidence of maternal morbidity following caesarean section was very minimum, of all the morbidity conditions, UTI was $17 \%$.One patient expired after caesarean section due to DIC, her caesarean section was done for abruption Placenta. As the incidence of 1stcaesarean section due to any cause is gradually rising. So subsequently, the incidence of repeat caesarean section is increasing in a double manner, because majority of obstetricians do not like trial of labour in a patient of previous caesarean section, doing straight a repeat caesarean section in patients with previous caesarean section. The rising trends in caesarean section rates should, therefore, be checked by studies. WHO recommends to put a limit to the rate of caesarean section at $10 \% \%^{9}$. This study was carried out with the objective to evaluate various aspect, such as incidence, indication, age, parity, maternal \& fetal complications of caesarean section. Though this study is not representative of whole population, it has provided certain data\& information of a particular institution. From this study we can take the information that judicious\& accurate decision \& early decision is to be taken in performing caesarean section because late decision may put the mother \& baby in moribund condition, inspite of caesarean section. Same type of study was done in BSSMMU on 2004 and showed that the common indication of caesarean section was previous caesarean section and second one was fetal distress. ${ }^{10}$

\section{Recommendations}

To reduce the post operative complications with caesarean section, some definitive measures should be taken during $\&$ after caesarean section:
1. To improve the health status of the mother during pregnancy by antenatal care.

2. To maintain proper asepsis measure.

3. Catheterization should be avoided if possible.

4. To educate the patient\& her relative about the importance of cleanliness.

\section{References}

1. D.C Dutta. Text book of Obstetrics. 7th edition.

2. Althabe F, Belizan JM. Caesarean section: the paradox. Lancet.2006;368:1472-3.

3. Betran AP, Merialdi M, Lauer JA, Bing- Shun W. Rates of caesarean section: analysis of global, regional \& national estimates. Paediator Perinat Epidemiol.2007;21(2):98113.

4. Althabe F, Sofa C, Belizan JM, Gibbas L, Jacquerioz F. Caesarean section rates maternal, neonatal mortality in low, medium \& high income countries: an ecological study. 2006;33(4):270-7.

5. C,Holtz S, Staqnton C. Socioeconomic differentials in cesarean section rates in developing countries: a retrospective analysis. Lancet.2006;368:1516-23.

6. Wikipedia, the free encyclopedia. http://en.wikipedia.org/wiki/c- section

7. Cesarean section -A brief history, part1http;//www.nlm.nih.gov/exhibition/ cesarean / part-1.

8. Safe prevention of the primary cesarean delivery--American congress of Obstetrician \& Gynecologist\& the society of Maternal \&Fetal Medicine: March2014.

9. WHO statement on cesarean section rates, 2015.

10. Dr. Sultana N, A clinical study of common indications of caesarean section in BSMMU, 2005. 